\title{
PROBING DEPTH AND PATIENT SATISFACTION WITH MANDIBULAR OVERDENTURES RETAINED BY FOUR VERSUS TWO MINI- IMPLANTS: RANDOMIZED CONTROLLED CLINICAL STUDY
}

\author{
May Mahmoud Hassan*, Ayman Gouda** and Eman Helal ${ }^{* *}$
}

\begin{abstract}
Background: Nowadays mandibular overdentures retained by mini-implants are used on a wide scale as a substitute for the conventional dental implant supported overdenture thus further studies are required to verify this replacement.

Methodology: Fourteen patients were randomly categorized into two equal groups. In the first group (Group I) patients received mandibular overdentures retained by four mini dental implants, while in the second group (Group II) patients received mandibular overdentures retained by two mini dental implants. All patients were scheduled for recall visits and probing depth was recorded at time of loading, six months and twelve months. Patient satisfaction was evaluated after six months of complete prostheses installation. For parametric data, Independent sample t-test was used to compare between two groups in non-related samples. Paired sample t-test was used to compare between two groups in related samples. For non-parametric data, Mann Whitney test was used to compare between two groups in non-related samples. Wilcoxon test was used to compare between two groups in related samples.
\end{abstract}

Results: Regarding probing depth: (Group I) was significantly lower than (Group II) after 6 and 12 months, while in patient satisfaction there was non-significant difference between the two groups in the first group of questions related to (general satisfaction, phonetics and aesthetics while there was significant difference in the second group of questions related to (prosthesis stability and comfort) between the two groups.

Conclusion: Within the limitations of this study : 1- The mandibular overdenture retained by Four mini-implants is recommended over mandibular overdenture retained by two mini-implants as it showed less bone resorption and improved patient satisfaction .

KEYWORDS: Patient satisfaction, edentulism, mini-implants, overdenture, probing depth

* Lecturer, Removable Prosthodontic Department College of Oral and Dental Surgery, Misr University for Science and Technology, Giza Egypt.

** Lecturer, Oral and Maxillofacial Surgery Department, Faculty of Dentistry, Cairo University, Cairo, Egypt.

*** Researcher, Fixed\& Removable Prosthodontics Dep., National Research Centre (NRC), Cairo, Egypt. 


\section{INTRODUCTION}

The process of rehabilitating edentulous patients is quite questionable because it involves correcting and restoring various variables such as speech, function and esthetics ${ }^{1,2}$. The use of rootform dental implants is based on the concept of osseointegration, which represents the essence of modern implantology ${ }^{3-8}$. Based on their diameter, dental implants with small diameter (between $1.8 \mathrm{~mm}$ and $3 \mathrm{~mm}$ ) are known as mini-implants while those with $3 \mathrm{~mm}$ diameter or more than 3 $\mathrm{mm}$ are conventional and wide dental implants ${ }^{4-8}$. Recent studies had demonstrated that the use of mini-implants in lower jaw with severe bone resorption have a positive impact on both treatment time and stability of the overdenture ${ }^{1,2,10-12}$ Since the small implant diameter permits its placement in areas having low bone thickness ${ }^{13}$. Although the use of conventional implants may be associated with a long-term success rate ${ }^{14,15}$, yet it still has its drawbacks that limit its use such as being costly and technically sensitive when inserted into bone with unfavorable dimensions especially in cases where bone grafting and nerve lateralization procedures are hampered by the presence of systemic disease ${ }^{17,8,16-18}$.

Mundt et.al have shown in their study high level of annual marginal bone loss for overdentures retained by mini implants especially in the maxillary arches more than in the mandibular arches after a mean observation period of two to three years ${ }^{4}$. On the other hand, Preoteasa ${ }^{18}$ et. al. have demonstrated in their studies accepted annual marginal bone loss without giving the enough attention to the status of the occlusion or the status of the opposing arch regarding the remaining natural teeth, ridge status and type of restoration.

Also on comparing four mini implant retained overdenture with two mini implant retained ${\text { overdenture Ribeiro }{ }^{19}}^{\text {et. }}$ al. concluded in their study that the use of four implants was associated with an increased perception of pain more than two implants.

The success of overdenture treatment is governed by many factors, and patient satisfaction is one of these factors to consider. When comparing implantsupported dentures with conventional dentures, the former was found to be associated with significantly fewer complications and higher levels of patient satisfaction. Patient satisfaction with dentures depends primarily on how well they restore normal oral function. This shows that clinician's evaluation should be abandoned when it comes to assessing patient satisfaction ${ }^{20,21}$.

However on reviewing the literature there were numerous studies on the mini dental implants and comparing it with the conventional dental implants ${ }^{1,2,22,23}$ but there have not yet been reliable studies focused on the effect of number of mini implants supporting the mandibular overdenture in relation to bone loss and patient satisfaction or improving the quality of life. Therefore, the purpose of this study was to evaluate the effect of number of mini-implants supporting the mandibular overdenture in terms of changes of probing depth around the mini-implants and improving the quality of life represented in evaluating the patient satisfaction.

The hypothesis for this study was null i.e. that there will be no influence of the number of the miniimplants supporting the mandibular overdenture on the probing depth changes by time also regarding patient satisfaction it was assumed there will be no difference between both treatment modalities.

\section{Methodology}

This study was conducted on fourteen male patients for standardization of the factors that may affect the bone loss; they were selected from the outpatient clinic, Faculty of Oral and Dental Surgery, Misr University for Science and Technology. Middle aged patients were preferred of 
an average age 55 years to avoid the possible effect of age related changes on mucosa, residual ridge and on the healing process of the surgical implant site. The selection criteria were depended on the patient's ability to receive implant-tissue supported overdenture hence all selected patients free from any medical conditions that might adversely affect the implant insertion procedure. Bone quantity and quality of all selected patient were checked by cone beam CT and there was no need for bone graft procedures. They were non-smokers and did not receive any radiotherapy or chemotherapy treatment

All the selected patients were informed about the procedure and motivated to the treatment, they agreed to co-operate and follow the instructions.

\section{Patient evaluation and examination}

Visual Intra oral examination was carried out, the mucosa covering the edentulous area was inspected to check for any sign of infection, irritation, inflammation or ulceration

Also, digital examination was carried out to detect the presence of any sharp bony spicules or the presence of wiry ridge, bone depth and width was evaluated by using cone beam $\mathrm{CT}$.

The fourteen patients were randomly allocated and categorized into two equal groups each of them included seven patients. Allocation followed a sequence of random numbers contained by sealed, opaque envelopes, which were prepared by a researcher without contact with other trial procedures. Numbers were generated by Microsoft Excel software (Microsoft Excel 2003; Microsoft Corporation) following a 1:1 ratio according to a simple randomization scheme. The first group (Group I: The Control group) received mandibular overdentures retained by four mini-implants, The second group (Group II: The Test group) received mandibular overdentures retained by two mini-implants.

Before surgical procedure, all patients were received upper and lower dentures and then the finished lower dentures of all patients were duplicated to construct surgical template.

\section{Mini implants installation}

According to the surgical and prosthetic considerations, implant site planning was performed.

Implants were placed $5 \mathrm{~mm}$ anterior from the mental foramen, and $5 \mathrm{~mm}$ were left between each mini dental implant, hence these positions were transferred to the gingiva of the patient and these positions also were marked with bleeding points. Holes were drilled at the mini-implants chosen sites to guide the insertion of the mini-implants. mini dental implants (INNO Dental implant, miniimplant system Korean), $1.8 \mathrm{~mm}$ in diameter, 15 $\mathrm{mm}$ in length, were placed in all patients. Drilling was started by a pilot drill of (1.1 mm diameter) was used with a pumping action and under a copious irrigation. Once the crestal cortical bone was perforated, drilling was advanced to about $1 / 3$ to $3 / 4$ implant length based on the bone drilling resistance. The implant was removed from the sterile vial and the tip of the implant was placed in a clockwise direction into the drilled sites by the implant mount cap which acts as initial driver. Once the bone resistance was engaged, the cap was discarded. The torque ratchet wrench was used to seat the mini dental implant into its final position at $35 \mathrm{~N} / \mathrm{cm}$ precustomized torque by using the winged thumb drive (Fig.1).

The undercut portions of the neck of the ball head abutments which is below O-ring level were blocked by pink wax (Modeling wax, Cavex, Holland) and the metal housings and rubber rings were loaded and seated over the balls of the implants.

The fitting surface of the denture was relieved at the implant sites to create enough room for the placement of the metallic housing. The denture`s fitting surface was painted with adhesive at these relieved areas (holes). Then auto polymerizing pink acrylic resin (Acroston heat-cured, Acroston Dental factory, Egypt under Excellsive license from 
WIW, England) was injected in the relieved holes then with normal occlusal pressure the denture were seated in the patient's mouth. After 5 minutes, the denture was removed and the excess material was trimmed. Digital panoramic radiograph was taken to check the implants (Fig 2).

All patients were recalled monthly to check the overdenture and the implant and to perform a proper oral hygiene measurement if needed.

All patients were evaluated clinically at baseline (during healing period), 6 months and 12 months later.

\section{Clinical evaluation}

\section{1) Probing pocket depth}

Graduated pressure sensitive probe (Vivacare
TPS, Vivadent, Schaan, Lichtenstein) was used and probing depth was measured at the midbuccal, mid-lingual, mid-mesial and mid-distal surfaces of the implants and the mean value for the scored surfaces for each implant was calculated.

\section{2) Patient satisfaction}

A questionnaire was used to evaluate patient satisfaction (Naert et al. 2004; Mericske-Stern et al. 2009; Elsyad 2012). Questionnaires were translated into Arabic before they were made available to all patients. They consist of two sections. The first part consisted of five questions (A to E) to which the patients should respond according to an ordered scale with numbers ranging from 1 (very bad) to 9 (excellent). The second section consists of five yes/ no questions ( $\mathrm{F}$ to $\mathrm{J}$ ).

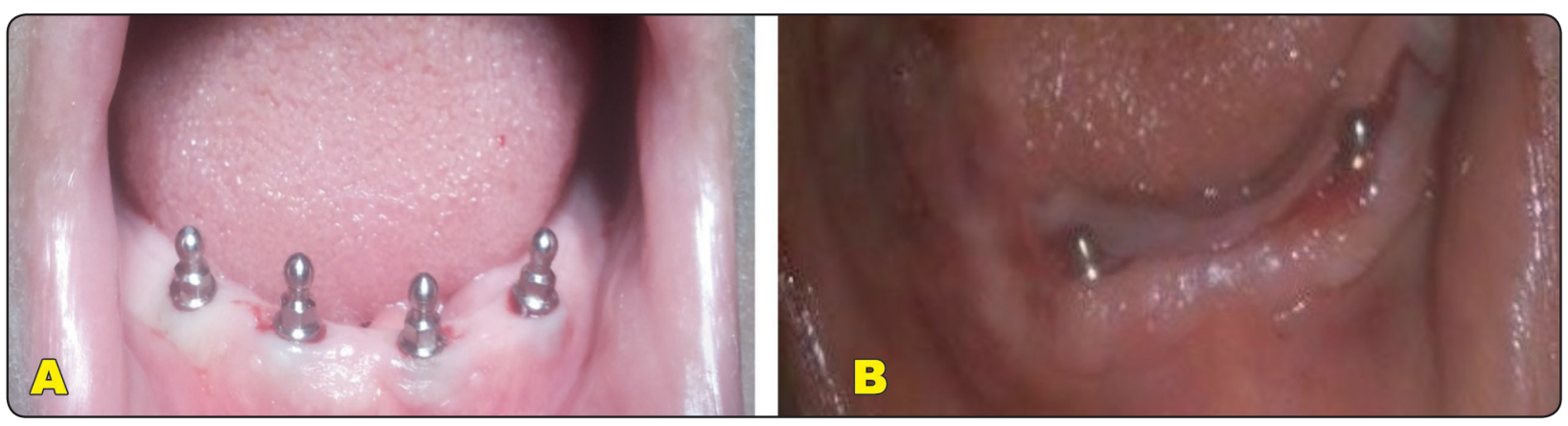

Fig. (1) (a): four mini-implant installed in Group I ), (b): two mini-implants installed in Group II)

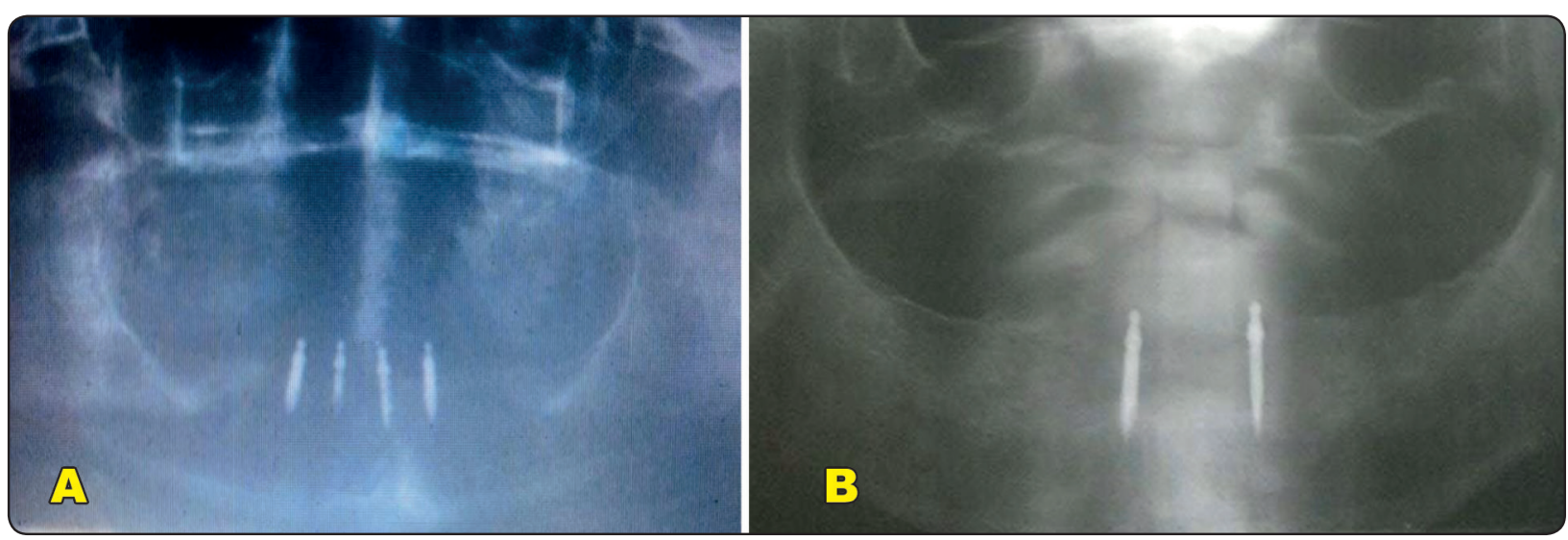

Fig. (2) : Digital panoramic radiograph view (a): Four mini-implants group),(b): Two mini-implants group) 


\section{First part}

A. How do you find your new implant retained complete overdenture in general?

B. How well does your new implant retained complete overdenture remain in place?

C. How well you can eat with your new implant retained complete overdenture?

D. How well can you talk with your new implant retained complete overdenture?

E. How do you find the appearance of your implant retained complete overdenture?

\section{Second part}

F. Do you avoid contact with other people because of fear losing your denture?

G. Does your new denture bother your mind?

H. Does food impaction occur under your denture?

I. Does your expectations became real with your new denture?

\section{$J$. Would you repeat the same treatment?}

The mean and standard deviation values were calculated for each group in each test. Data were explored for normality using Kolmogorov-Smirnov and Shapiro-Wilk tests, probing depth data showed parametric (normal) distribution, while satisfaction data showed non-parametric (not-normal) distribution.

For parametric data, Independent sample t-test was used to compare between two groups in nonrelated samples. Paired sample t-test was used to compare between two groups in related samples.

For non-parametric data, Mann Whitney test was used to compare between two groups in nonrelated samples. Wilcoxon test was used to compare between two groups in related samples.

The significance level was set at $\mathrm{P} \leq 0.05$. Statistical analysis was performed with IBM ${ }^{\circledR}$ SPSS $\AA^{\circledR}$ Statistics Version 20 for Windows.

\section{RESULTS}

1) For Probing depth: probing depth for two mini implants group was $3.69 \pm 0.30,4.45 \pm 0.25$ while in the four implants group was $1.62 \pm 0.21$, $2.29 \pm 0.34$ after six and twelve months respectively.

Statistical analysis revealed significant difference between the $6 \mathrm{~m}$ and $12 \mathrm{~m}$ periods within each group where $(p<0.001)$ (Table1) and significant differences between (The Two mini- implants) and the (The Four mini-implants) groups at both evaluation follow up periods (six months and twelve months) where $(p<0.001)$ and (Figure 3$)$.

TABLE (1): The mean, standard deviation (SD) values of probing depth of different groups

\begin{tabular}{|c|c|c|c|c|c|}
\hline \multirow{2}{*}{ Variables } & \multicolumn{3}{|c|}{ Probing depth } & \multirow{2}{*}{ } \\
\cline { 2 - 5 } & Two implants & \multicolumn{2}{|c|}{ Four implants } & \multirow{2}{*}{-value } \\
\cline { 2 - 5 } & Mean & SD & Mean & SD & \\
\hline $6 \mathrm{~m}$ & 3.69 & 0.30 & 1.62 & 0.21 & $\mathrm{p}<0.001$ \\
\hline $12 \mathrm{~m}$ & 4.45 & 0.25 & 2.29 & 0.34 & $\mathrm{p}<0.001$ \\
\hline $\mathrm{p}$-value & $\mathrm{p}<0.001$ & $\mathrm{p}<0.001$ & \\
\hline
\end{tabular}

*; significant $(p<0.05) \quad n s ;$ non-significant $(p>0.05)$

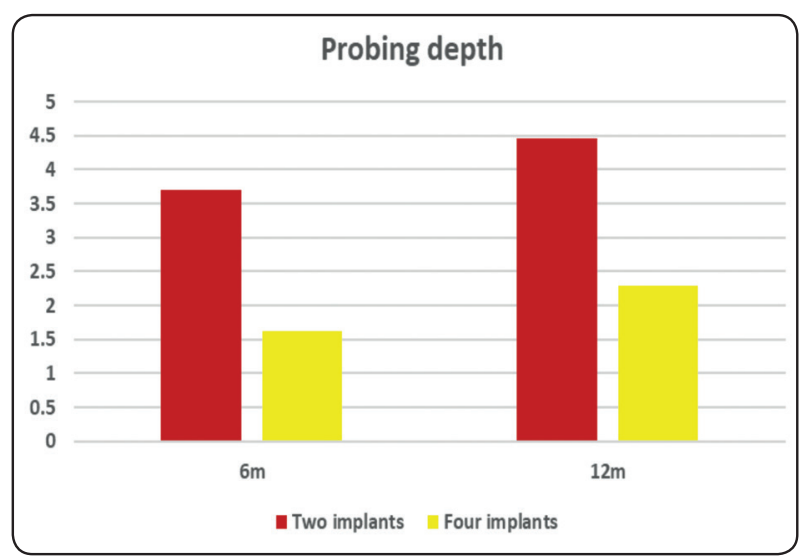

Fig. (3) Bar chart representing probing depth for different groups. 


\section{2) For the patient satisfaction}

Patient satisfaction after six months derived from questions concerning general satisfaction, phonetics and aesthetics revealed non statistically significant differences between the (Two mini-implants) and (Four mini-implants) groups where $(\mathrm{p}>0.05)$
(Table 2).

Also regarding the second part questions series related to prosthesis stability and chewing comfort there were significant differences between both groups $(p<0.001)$ (Table 3$)$

TABLE (2) The mean, standard deviation (SD) and median values of satisfaction in the two groups

\begin{tabular}{|c|c|c|c|c|c|c|c|}
\hline \multirow{2}{*}{ Variables } & \multicolumn{7}{|c|}{ Patient Satisfaction (First part) } \\
\cline { 2 - 9 } & \multicolumn{3}{|c|}{ Two implants } & \multicolumn{3}{c|}{ Four implants } & p-value \\
\cline { 2 - 9 } & Mean & SD & Median & Mean & SD & Median \\
\hline Question A & 6.71 & 1.80 & 7 & 7.14 & 1.57 & 7 & $0.650 \mathrm{~ns}$ \\
\hline Question B & 6.57 & 0.79 & 6 & 6.29 & 1.38 & 7 & $0.893 \mathrm{~ns}$ \\
\hline Question C & 7.43 & 0.53 & 7 & 6.71 & 1.50 & 7 & $0.281 \mathrm{~ns}$ \\
\hline Question D & 8.00 & 0.82 & 8 & 7.29 & 0.95 & 8 & $0.192 \mathrm{~ns}$ \\
\hline Question E & 7.86 & 0.69 & 8 & 7.83 & 1.17 & 8 & $0.879 \mathrm{~ns}$ \\
\hline
\end{tabular}

*; significant $(p<0.05) \quad n s ;$ non-significant $(p>0.05)$

TABLE (3): Number and the \% of patients responding to yes or no question type values of satisfaction of two groups

\begin{tabular}{|c|c|c|c|c|c|c|}
\hline & & \multicolumn{5}{|c|}{ Satisfaction (Second part) } \\
\hline \multicolumn{2}{|c|}{ Variables } & \multicolumn{2}{|c|}{ Two implants } & \multicolumn{2}{|c|}{ Four implants } & \multirow{2}{*}{ p-value } \\
\hline & & $\mathrm{n}$ & $\%$ & $\mathrm{n}$ & $\%$ & \\
\hline \multirow{2}{*}{ Question F } & Yes & 2 & $28,6 \%$ & 0 & $0 \%$ & \multirow{2}{*}{$0.141 \mathrm{~ns}$} \\
\hline & No & 5 & $71.4 \%$ & 7 & $100 \%$ & \\
\hline \multirow{2}{*}{ Question G } & Yes & 3 & $42.9 \%$ & 1 & $14.3 \%$ & \multirow{2}{*}{$0.254 \mathrm{~ns}$} \\
\hline & No & 4 & $57.1 \%$ & 6 & $85.7 \%$ & \\
\hline \multirow{2}{*}{ Question H } & Yes & 5 & $71.4 \%$ & 0 & $0 \%$ & \multirow{2}{*}{$0.007^{*}$} \\
\hline & No & 2 & $28.6 \%$ & 7 & $100 \%$ & \\
\hline \multirow{2}{*}{ Question I } & Yes & 3 & $42.9 \%$ & 0 & $0 \%$ & \multirow{2}{*}{$0.060 \mathrm{n}$} \\
\hline & No & 4 & $57.1 \%$ & 7 & $100 \%$ & \\
\hline \multirow{2}{*}{ Question J } & Yes & 3 & $42.9 \%$ & 7 & $100 \%$ & \multirow{2}{*}{$0.023^{*}$} \\
\hline & No & 4 & $57.1 \%$ & 0 & $0 \%$ & \\
\hline
\end{tabular}

*; significant $(p<0.05) \quad n s ;$ non-significant $(p>0.05)$ 


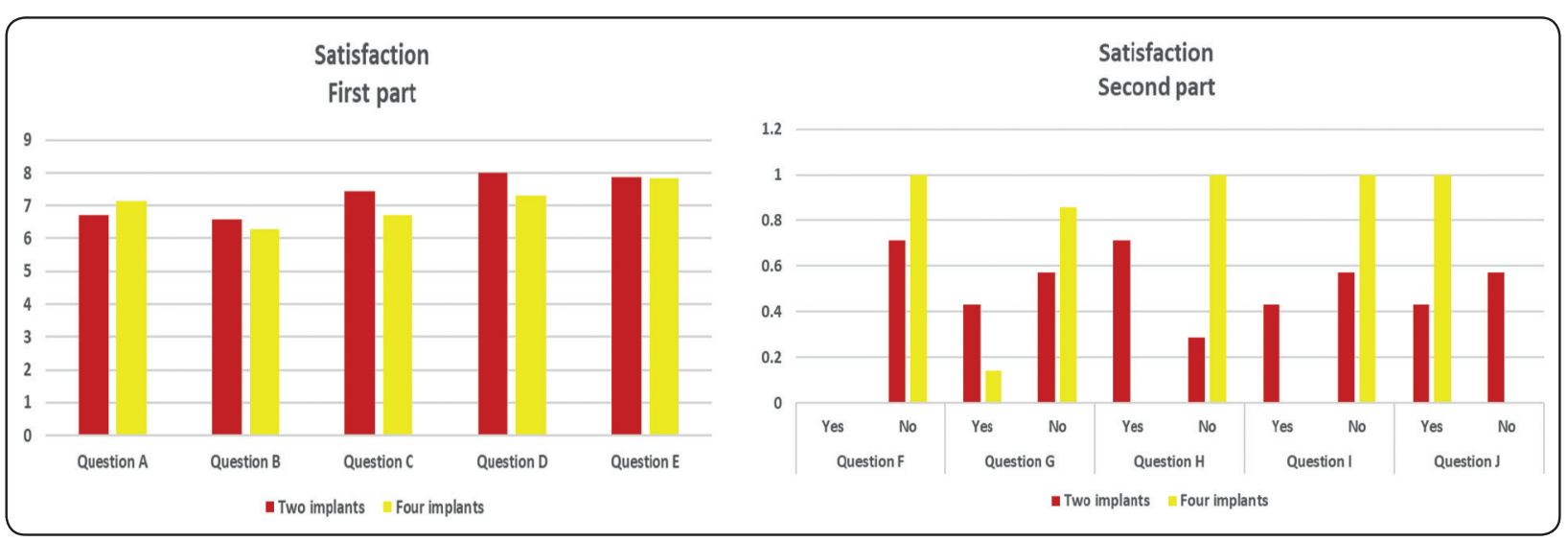

Fig. (4): Bar chart representing satisfaction for the two groups

\section{DISCUSSION}

The results of the current study revealed a significant increase in bone loss around the miniimplants in the test group compared to the control group that showed lower probing depth values collected during the postoperative period after six and twelve months intervals. Hence these results rejected the null hypothesis of no difference between both groups and suggested that increasing the number of mini-implants supporting the mandibular over-denture may be influential on conserving the remaining bone of the mandible.

The results of this study showed that the mean probing depth of the two mini-implant group was 3.69 after six months and then increased to 4.45 after twelve months. While in the four implant group the mean of the probing depth after six months was 1.62 and then increased slightly to be 2.29 after twelve months. This significant difference in bone resorption between the two groups may be attributed to the increased implants number which offers greater surface area for support, in addition to the better stress distribution and less torque effect. ${ }^{24-26}$.

There was also a statistically significant difference between six months and twelve months within the same group for both treatment modalities.
Increasing in bone loss after six months is more than bone loss occurring after twelve months in both groups which may be due to the fact of bone remolding occurs within the first six months ${ }^{24,27,28}$ and any increase in probing depth at twelve months is due to an undesirable occlusion forces subjected to the prothesis which may be considered an indication of restoration failure ${ }^{26,29-33}$.So more longitudinal studies with large sample size are required to emphasize that increasing the number of implants supporting the prostheses is beneficial.

The results of this study contradict the findings of other studies which state that using the minimal number of implants to support the restoration is advantageous in terms of preserving the periimplant soft tissues and bone contours and that using four implants do not provide any advantages over using two implants in the term implant stability ${ }^{34-36}$. However, the difference in our findings can be attributed to the difference in the size between the mini-implants and conventional implants as the large diameter of the latter enable it to provide better support and stress distribution.

Evaluation of the patient satisfaction regarding their oral condition is proved in the last years to be as important as evaluating the pure mechanical behavior of the prosthesis. In order to evaluate the patient satisfaction, the tool of evaluation had 
to cover function of the prostheses and allow the patient to present his experience with the restoration in an objective form to exclude any chance of bias. Satisfaction with overdentures was investigated through two questionnaires (Naert et al. 2004; Mericske-Stern et al. 2009) the questionnaires were given to the patients in Arabic to be understood easily ${ }^{37}$.

The results of the study revealed non-significant difference between both groups regarding the first part of questionnaire (related to phonetics and esthetics) which support the null hypothesis that as long as there is no significant difference between the two treatment modalities so it is preferred to rely on the minimal simple treatment of edentulous mandible (two mini-implant) to decrease surgical intervention, time and cost of the treatment ${ }^{9}$.

But regarding the second part of the questionnaire (related to prosthesis stability and chewing ability), the difference appeared at the questions about food impaction under the prosthesis which may be due to increased occlusal load in the cases of the (two miniimplant overdenture) as reported by Elias $\boldsymbol{e}$ t. $\boldsymbol{a l}^{38}$ that increasing the occlusal load may increase the risk of food impaction. The other question showed difference was regarding if the patient would repeat the same treatment or not the results was in the favor of the (four mini-implant group) and this may be attributed to the discomfort experienced by the patient in (two mini- implants) due to bone resorption around the dental mini-implants in this group which lead to increased risk of food impaction, Peri-implantitis, pain and discomfort accordingly .all of these factors may affect the patient's opinion regarding the prosthesis as interpreted by $\boldsymbol{B r i a n}^{39}$ in his systematic review about the standard care of edentulous mandible that the pain and discomfort experienced after the implantation procedure in addition to the economic status of the patient may affect his decision regarding the prosthesis.
Questions regarding the retention of the overdenture during speech ,discomfort and if the prosthesis met the expectations or not revealed nonsignificant difference.

Scepanouic et. al..$^{40,41}$ in their study reported increase in patient satisfaction after few months of delivery ,they suggested that this improvement may be due to increased stability and retention of the prostheses due to the improvement of the adaptation of the prosthesis which accordingly decrease discomfort.

Hence, these results rejected the null hypothesis of no difference between both groups and confirmed that increasing the number of mini-implants supporting the mandibular over-denture is influential on conserving the remaining bone of the mandible and has positive effect on the patient satisfaction as well.

\section{CONCLUSIONS}

So within the limitation of this study and time frame it was concluded that:

1- Increasing the number of mini-implants supporting the mandibular overdenture has great effect on conserving the residual bone of the mandibular edentulous ridge and decreasing the bone loss around the mini-implants supporting the overdenture.

2- The cases of the (four mini-implant group) were more satisfied with their prosthesis than the cases of (the two mini-implant groups) which support the same suggestion of increasing the miniimplant number supporting the overdenture.

3- More longitudinal studies with larger sample size are required associating different factors with the bone loss around the mini-implants supporting mandibular overdentures . 


\section{REFERENCES}

1. Lemos CAA, Verri FR, Batista VE de S, Júnior JFS, Mello CC, Pellizzer EP. Complete overdentures retained by mini implants: A systematic review. J Dent. 2017;57:4-13. doi:10.1016/j.jdent.2016.11.009

2. Al-Harbi F. Mandibular implant-supported overdentures: Prosthetic overview. Saudi J Med Med Sci. 2018;6(1):2. doi:10.4103/sjmms.sjmms_101_17

3. Abdunabi A, Morris M, Nader SA, de SOUZA RF. Impact of immediately loaded implant-supported maxillary fullarch dental prostheses: A systematic review. J Appl Oral Sci. 2019;27:1-15. doi:10.1590/1678-7757-2018-0600

4. Mundt T, Schwahn C, Biffar R, Heinemann F. Changes in Bone Levels Around Mini-Implants in Edentulous Arches. Int J Oral Maxillofac Implants. 2015;30(5):1149-1155. doi: $10.11607 /$ jomi.4012

5. Prosthodontics R. Interventions for edentate elders - what is the evidence ? 2014;31:44-51. doi:10.1111/ger.12083

6. B. W. Darvel, R. K. F. Clark. The physical mechanisms of complete denture retention. Br Dent J. 2000;189(5):248252.

7. Sahar A. Kortam and Reem M. Abdeen. Prosthetic complications and maintenance of implant retained maxillary and mandibular overdentures occlusal schemes: randomized controlled clinical study. 2021;67:2321-2332.

8. Alfadda SA, Frcd C, Amri MD Al, Prosthodontics MS, Alohali FCA. Do Clinical Denture Quality and Inter-Implant Distance. 2017;30(6):519-525. doi:10.11607/ijp.5295

9. Park J-H, Lee J-Y, Shin S-W. Treatment Outcomes for Mandibular Mini-Implant-Retained Overdentures: A Systematic Review. Int J Prosthodont. 2017;30(3):269276. doi:10.11607/ijp.4929

10. Schwindling FS, Schwindling FP. Mini dental implants retaining mandibular overdentures: Adental practice-based retrospective analysis. J Prosthodont Res. 2016;60(3):193198. doi:10.1016/j.jpor.2015.12.005

11. Lee E, Shin SY. The influence of the number and the type of magnetic attachment on the retention of mandibular mini implant overdenture. J Adv Prosthodont. 2017;9(1):14-21. doi:10.4047/jap.2017.9.1.14

12. AUNMEUNGTONG W, , P. KHONGKHUNTHIAN PR. Different Mini Dental Implant Designs Using in Implant Retained Overdenture : Published online 2016:202-212.
13. Respg M. Survival of Mini Dental Implants Used to Retain Mandibular Complete Overdentures: Published online 2019. doi:10.11607/jomi.6991

14. Papaspyridakos P, Mokti M, Chen C. Implant and Prosthodontic Survival Rates with Implant Fixed Complete Dental Prostheses in the Edentulous Mandible after at Least 5 Years : Published online 2013:1-13. doi:10.1111/cid.12036

15. Vogel R, Smith-palmer DDSJ, Valentine DW. Evaluating the Health Economic Implications and Cost-Effectiveness of Dental Implants : A Literature Review. Published online 2013. doi:10.11607/jomi.2921

16. Chen K, Lin T, Liu P, Ramp LC, Lin H, Wu C. O ral Rehabilitation An analysis of the implant-supported overdenture in the edentulous mandible. 2013;(4). doi: $10.1111 /$ joor.12010

17. Rg L, Frfr N, Rädel M, Reissmann DR. 5-year randomized multicenter clinical trial on single dental implants placed in the midline of the edentulous mandible running title: single dental implants in the edentulous mandible. :0-2. doi:10.1111/clr.13692

18. Preoteasa E, Imre M, Preoteasa CT. A 3-year follow-up study of overdentures retained by mini-dental implants. 2014;29(5). doi:10.11607/jomi.3222

19. Ribeiro AB, Vecchia MP Della, Cunha TR, Sorgini DB, Dos AC. Short-term post-operative pain and discomfort following insertion of mini-implants for retaining mandibular overdentures : a randomized controlled trial. 2015;(4). doi:10.1111/joor.12287

20. Elsyad MA. Patient satisfaction and prosthetic aspects with mini-implants retained mandibular overdentures . A 5-year prospective study. Published online 2015:1-8. doi:10.1111/ clr. 12660

21. Bchd DPM, Bchd NJA. Patient-based outcomes with conventional or mini-implants immediately loaded with locator-retained mandibular overdentures : A cohort study. 2020; (September): 1-7. doi:10.1111/cid.12955

22. De Souza RF, Ribeiro AB, Della Vecchia MP, et al. Mini vs. standard implants for mandibular overdentures: A randomized trial. J Dent Res. 2015;94(10):1376-1384. doi: $10.1177 / 0022034515601959$

23. Kim Y. Mini Implant-Retained Complete Overdenture Can be an Alternative Treatment Option for Selected Patients. J Evid Based Dent Pract. 2017;17(2):116-118. doi:10.1016/j.jebdp.2017.04.003 
24. Wang L, Wu Y, Perez KC, et al. Effects of Condensation on Peri-implant Bone Density and Remodeling. Published online 2017. doi:10.1177/0022034516683932

25. Lin D, Li Q, Li W, Swain M. Review article Dental implant induced bone remodeling and associated algorithms. J Mech Behav Biomed Mater. 2009;2(5):410-432. doi:10.1016/j.jmbbm.2008.11.007

26. Irandoust S, Müftü S. The interplay between bone healing and remodeling around dental implants. Published online 2020:1-10. doi:10.1038/s41598-020-60735-7

27. Chou H, Jagodnik JJ, Mu S. Predictions of bone remodeling around dental implant systems. 2008;41:1365-1373. doi:10.1016/j.jbiomech.2008.01.032

28. Neill JEO, Yeung SC. Do dental implants preserve and maintain alveolar bone? Published online 2011:229-235. doi:10.1111/j.2041-1626.2011.00074.x

29. Liddell RS, Ajami E, Li Y, Bajenova E, Yang Y, Davies JE. The Influence of Implant design on the Kinetics of Osseointegration and Bone Anchorage Homeostasis. Acta Biomater. Published online 2020. doi:10.1016/j.actbio.2020.11.043

30. Li J, Yin X, Huang L, et al. Relationships among Bone Quality , Implant Osseointegration , and Wnt Signaling. Published online 2017. doi:10.1177/0022034517700131

31. Eser A, Tonuk E, Akca K, Dard MM, Cavit M. Predicting bone remodeling around tissue- and bone-level dental implants used in reduced bone width. J Biomech. 2013;46(13):22502257. doi:10.1016/j.jbiomech.2013.06.025

32. Consolaro A. Miniplates and mini-implants : bone remodeling as their biological foundation 1. 2015; 20(6):16-31.

33. Lin D, Li Q, Li W, Duckmanton N, Swain M. Mandibular bone remodeling induced by dental implant. J Biomech. 2010;43(2):287-293. doi:10.1016/j.jbiomech.2009.08.024
34. Al-magaleh WR, Swelem AA, Radi IAW. The effect of 2 versus 4 implants on implant stability in mandibular overdentures : A randomized controlled trial. J Prosthet Dent. 118(6):725-731. doi:10.1016/j.prosdent.2016.12.008

35. Pisani MX, Presotto AGC, Mesquita MF, Barão VAR, Kemmoku DT, Del Bel Cury AA. Biomechanical behavior of 2-implant- and single-implant-retained mandibular overdentures with conventional or mini implants. J Prosthet Dent. 2018;120(3):421-430. doi:10.1016/j.prosdent.2017.12.012

36. Nischal K, Mishra SK. Crestal Bone Changes and Patient Satisfaction with Single Implant-Retained Mandibular Overdentures with Dalla Bona and Locator Attachments with Immediate Loading Protocols. A Randomized Controlled Clinical Study. 2020;00: 1-10. doi:10.1111/ jopr.13230

37. Elsyad MA. Patient satisfaction and prosthetic aspects with mini-implants retained mandibular overdentures . A 5-year prospective study. Published online 2015:926-933. doi:10.1111/clr.12660

38. Wang D, Zhang X, Zhang C, Jiang L, Deng C, Zhao B Clinical assessment of food impaction after implant restoration : a retrospective analysis. 2021;2061:6-11.

39. Brian Fitzpatrick. Standard of care for the edentulous mandible: A systematic review. 2006;(January):71-78

40. Pjetursson BE, Karoussis I, Bu W, Bra U, Lang NP. Patients' satisfaction following implant therapy A 10-year prospective cohort study. 2005; (Bra 1969):185-193. doi:10.1111/j.1600-0501.2004.01094.x

41. Toia M, Wennerberg A, Torrisi P, Farina V, Corrà E, Cecchinato D. Patient satisfaction and clinical outcomes in implant- supported overdentures retained by milled bars : Two-year follow- up. 2019; (September 2018): 624-633. doi:10.1111/joor.12784 